\title{
Engineering development of flexible selectivity grids for Nephrops
}

\author{
H. Loaec ${ }^{a}$, F. Morandeau ${ }^{b}$, M. Meillat ${ }^{b}$ and P. Davies ${ }^{a,{ }^{*}}$
}

\author{
${ }^{a}$ Materials and Structures group, Centre de Brest, IFREMER (French Ocean Research Institute) 29280 \\ Plouzané, France \\ ${ }^{\mathrm{b}}$ Fishing Technology group, Centre de Lorient, IFREMER (French Ocean Research Institute) 56100 \\ Lorient, France \\ *: Corresponding author : Tel.: +33 298224777; fax: +33 29822 4535; email : pdavies@ifremer.fr
}

\begin{abstract}
:
There are different approaches to selectivity, including increasing cod-end mesh size, square mesh panels and rigid grids. Selectivity grids have traditionally been produced to be as rigid as possible to maintain spacing but this can result in heavy, expensive grids, handling problems and brittleness. This paper presents an alternative approach using flexible polyurethane polymers to produce lightweight inexpensive grids with much improved damage tolerance and ease of handling, which also possess interesting selectivity characteristics. The material selection, design and development tests are described first, then preliminary sea trial results are presented. A flexible grid with a $20 \mathrm{~mm}$ spacing between bars performed successfully and enabled a reduction in juvenile catch of $87 \%$ by weight to be achieved, but also significant loss of commercial catch. Further development will concentrate on reducing the spacing to optimise selectivity.
\end{abstract}

Keywords: Selectivity; By-catch; Size selection; Grid; Nephrops; Polyurethane; Damage resistance 


\title{
Engineering Development of Flexible selectivity grids for Nephrops.
}

\author{
Loaec $\mathrm{H}^{1}$, Morandeau $\mathrm{F}^{2}$, Meillat $\mathrm{M}^{2}$, Davies $\mathrm{P}^{1 *}$
}

IFREMER (French Ocean Research Institute)

1. Materials and Structures group, Centre de Brest, 29280 Plouzané, France

2. Fishing Technology group, Centre de Lorient, 56100 Lorient, France

\begin{abstract}
There are different approaches to selectivity, including increasing cod-end mesh size, square mesh panels and rigid grids. Selectivity grids have traditionally been produced to be as rigid as possible to maintain spacing but this can result in heavy, expensive grids, handling problems and brittleness. This paper presents an alternative approach using flexible polyurethane polymers to produce lightweight inexpensive grids with much improved damage tolerance and ease of handling, which also possess interesting selectivity characteristics. The material selection, design and development tests are described first, then preliminary sea trial results are presented. A flexible grid with a $20 \mathrm{~mm}$ spacing between bars performed successfully and enabled a reduction in juvenile catch of $87 \%$ by weight to be achieved, but also significant loss of commercial catch. Further development will concentrate on reducing the spacing to optimise selectivity.
\end{abstract}

\section{Keywords}

Selectivity, By-catch, Size selection, Grid, Nephrops, Polyurethane, Damage resistance.

* Corresponding author pdavies@ifremer.fr, Tel. 0033 298224777, Fax. 0033298224535 


\section{Introduction}

Pressure on fishing stocks has led to extensive research into selectivity devices in recent years. An ICES (International Council for the Exploration of the Sea) document provides an overview of selection gear and methods for evaluating their effectiveness (Wileman et al. 1996). Selection may be used to reduce by-catch and/or to improve size selection. Various ways of allowing juveniles to escape from nets have been investigated such as imposing larger mesh size (Briggs 1999), sieve nets (Polet et al. 2004), or escape windows (Madsen 1999). An alternative approach which appears promising is the inclusion of a grid in the net, as shown in Figure 1 for nephrops. Grids have been used for some years and are currently the subject of considerable research . The Fishing Technology group of IFREMER in Lorient has been developing a metallic grid for monkfish since 1993, derived from the Nordmore grid (Meillat 1994). Sea trials were performed on a commercial vessel in Spring 1996. They showed that the use of a rectangular grid in the codend could allow up to $60 \%$ of juvenile benthic fish to escape (ray, monkfish, hake, megrim). In spite of promising results with grids there remains considerable debate over the merits of different types of selection gear. In the early 1990's it was shown that for cod the selection characteristics of grids were sharper than in codend meshes (Larsen \& Isaksen 1993). Graham et al reported recently (2004) that the addition of a grid in the extension reduced the selection range for haddock. However, Kvamme \& Isaksen (2004) have presented results which indicated similar selection ranges for grid and codend selectivity for cod, while the NETRASEL project for Nephrops also concluded that, in comparison with the 70 and $80 \mathrm{~mm}$ codend, selection grids offered no real advantage (Frid 2001). Simply increasing mesh size may therefore be adequate to achieve the required selectivity, but this may not be the case for multi-species fisheries. The clogging 
characteristics of inclined grids may also differ from those of codends when large catches are involved. The debate on the relative merits of different methods is still open, and will be addressed in the discussion section below, but that is not the main aim of the present paper. Here we are interested in the use of a novel approach to grid manufacture, namely the development of lightweight flexible grids, and their use for size selection of Nephrops. The aim of this paper is simply to show the development of a flexible grid and to present results from preliminary sea trials.

The Nephrops fishery suffers from a large by-catch as net mesh sizes are small for Nephrops compared to white fish trawls. The combination of undersize commercial fish species and undersize Nephrops can be as much as $60 \%$ by number resulting in high discards. A means of separating these in the net is essential if stocks are to be maintained, and most of the work reported in this area has been concerned with by-catch reduction rather than size selection. Several recent papers discuss the use of grids for bottom trawl fishing. Isaksen (1992) showed that rigid metallic grids were effective for separating shrimp from fish. Graham (2003) used the so-called Nordmore rigid grid for by-catch reduction with brown shrimp. Polet (2002) used a similar grid design for by-catch reduction off the Belgian and Dutch coasts. He found a significant reduction in fish capture but also a $15 \%$ reduction in commercial brown shrimp. Clogging was significant in some cases and could make acceptance by the fishing industry difficult. Fonseca et al (2005) reported on the use of grids, for the Portuguese crustacean trawl industry, and also showed high rates of by-catch exclusion, but again expressed concern over loss of target species.

Various materials have been employed for this application. Initially metallic grids were used and stainless steel has proved quite efficient. However, as pointed out by Grimaldo \& Larsen 
recently (2005) 'steel grids have been associated with handling problems due to their excessive weight, especially in bad weather'. Eigaard \& Holst (2004) also reported 'marked signs of tear and wear' on their grid section and recommended further research to establish the optimal design. Various plastics including polyamide, HMPE, PVC, ABS and even carbon fibre composites have been tried. Grimaldo \& Larsen suggested a new grid design, the 'Cosmos grid', in 2005, based on fibre glass and polyamide materials but their main concern was to improve water flow to reduce shrimp losses. Within the European project EUROGRID polyamide grids were evaluated, but these were costly to produce as they were machined from thick plates. Also, in order to pass over drum rollers these grids may need to be produced in sections and hinged, and the hinge may be a source of weakness.

An internal study at IFREMER was therefore started in 2001 to examine alternative designs and materials in order to develop a damage tolerant grid without hinges. The design requirements for this application include;

- sufficient stiffness to maintain opening during fishing,

- ability to pass over the drum roller without damage,

- light weight,

- impact resistance,

- $\quad$ low cost.

It was initially thought that grids would need to be very stiff to maintain the spacing between bars, but trials at sea and in test tanks indicated that static loads are quite low during fishing, the most severe loading is seen during the passage over the drum at the end of the haul. This suggested that a very flexible material combined with a short bar design might be appropriate. The present paper presents a detailed discussion of the material development together with 

procedure (ISO 37). 2002.

\section{Materials}

results from a preliminary campaign to evaluate this type of flexible grid for Nephrops in

Polyurethane (PU) was selected for this application for several reasons: First, the Ureol PU range developed by Ciba which was adopted here is well-suited to prototype development as it can be easily modified to enable a wide range of tensile properties (stiffness, strength and elongation to failure) to be obtained. This is because the system is based on several different liquid isocyanates and curing agents; by varying their proportions the polyurethane molecular structure is modified and hardness values from 30 Shore A to 65 Shore D can be obtained with the same ingredients. It is therefore not necessary to change the basic polymer chemistry. Shore hardness is widely used to characterise rubbery plastics and is measured by determining the resistance of the material to an indenter pushed into it with a special graduated tool. These values correspond to materials from very supple rubbers (the Shore A scale) to hard plastics (Shore D). Within each scale higher values indicate harder materials. The possibility to vary hardness was very important here as at the outset it was not clear what combination of stiffness and strength would be best-suited to this application. The low hardness materials are extremely flexible while increasing hardness allows improved stiffness and strength to be obtained, Figure 2. The results in this figure show nominal stress and strain values recorded in tensile tests; these are calculated as applied force divided by initial cross section and extension divided by the specimen length between grips. This follows a standard test 
121 Second, there was considerable experience with this polymer in other marine applications

122 and it was known, from a detailed internal study, that aging of the material selected would

123 allow several years of use at sea. Laboratory aged specimens retained their strength very well

124 after long immersion periods in artificial sea water at elevated temperatures, Figure 3. A

125 small loss in strength was noted when tests were performed on wet specimens but specimens

126 dried to constant weight showed no significant strength loss even after 2 years of accelerated

127 aging. Immersion of samples at sea for up to 5 years confirmed these results.

Fabrication

130

131 A major benefit of these PU systems is that large components can be cast into moulds at room

132 temperature and post-curing at elevated temperature is not necessary. Figure 4 shows an

133 example. Resin components are mixed and out-gassed and then poured directly into a wooden

134 mould. This allows design modifications to be rapidly implemented. Quite thick sections

$135(>20 \mathrm{~mm})$ have been produced with very few voids.

137 While this fabrication method is quite adequate for prototypes and small quantities, the resin

138 can also be injected into a closed mould once the design has been finalised. This allows larger

139 numbers of grids to be produced more quickly and cheaply for industrial use. Following the

140 prototype developments reported here injected grids with circular bars have been produced.

142 Cost is an important aspect of the overall performance of a grid. The exact price of a grid will

143 depend on where it is produced (labour costs) and the number required (whether investment in

144 a closed mould is economical or whether hand casting into an open mould is cheaper). 
145 Nevertheless, based on hand casting of several grids during this development programme it is

146 estimated that the cost of a flexible polyurethane grid will be less than half that of an 147 equivalent machined polyamide version of the type used in the EUROGRID project. This 148 could be reduced further if standard grid dimensions justify changing to a closed mould 149 technique.

151 Laboratory Evaluation results

153 A series of tests has been performed in the laboratory, first to characterise the grid elements 154 (bars), then to study the connections between these elements and finally to evaluate the 155 complete grids.

157 i) Bar elements

158 The basic element in the prototype grid is the bar, typically a beam of rectangular section 13 159 by $20 \mathrm{~mm}^{2}$. Tests were performed on these beams in flexure to examine their stiffness and 160 failure behaviour. A three-point flexure fixture was used with a loading rate of $5 \mathrm{~mm} / \mathrm{minute}$.

161 Figure 5 shows an example of the flexural response of a rectangular $13 \mathrm{~mm}$ thick $20 \mathrm{~mm}$ wide 162 grid element, tested in the (thinner) direction which is the direction which must resist opening 163 to maintain the selectivity. In addition to the material hardness the flexural rigidity is strongly 164 dependent on the thickness and the span length, so during the design development these two 165 parameters were adjusted, by increasing thickness and reducing span, in order to obtain a very 166 stiff bar design. However, it is important to note that even this high hardness (Shore 50D)

167 element did not break in flexure but deformed with the loading point until the test was 168 stopped. 
170 ii) Connections

171 The connections between the bars are potentially the weakest part of the grid. A series of 172 connecting elements, Figure 6a, was cut from grids and subjected to various loadings 173 including tension and torsion. The use of finite element analysis, Figure $6 \mathrm{~b}$, was valuable in 174 both developing these tests (determining loading points) and in examining the influence of the 175 radius of curvature on performance. This technique involves creating a model by 176 discretization of the component into small elements, using commercial software (FEMLAB ${ }^{\mathrm{TM}}$

177 here). The material properties (such as the stress-strain plots in Figure 2) are then entered. The 178 model can then be subjected to different loads and the response in critical areas can be 179 examined before choosing the most suitable test configuration to highlight these.

181 iii) Complete grid tests

182 The laboratory evaluation was completed by folding tests on complete grids, Figure 7. A 100183 ton capacity hydraulic test frame with a 1.5 metre course piston at the IFREMER Brest Centre 184 was employed for these tests.

185 The final design of grid (Shore hardness 50D) was folded in half several hundred times but no 186 damage was detected. Based on this experience trials at sea were initiated, using the grid 187 described in Figure 8. This is the same as that shown in Figure 7 except for an additional 188 escape window at the top.

\section{Preliminary Sea Trial results}

192 Several test campaigns with the IFREMER research vessel N/O Gwen Drez enabled this first 193 version of the grid to be evaluated before proposing it to the fishing industry. The Gwen Drez 
194 is a 25.5 meter long research vessel, (GRT 106t, engine power $440 \mathrm{~kW}$ ). The first tests, which

195 will be presented here, were performed in April 2002 (during the SELMERL1 campaign) and

196 a $20 \mathrm{~mm}$ spacing grid was used. These tests were intended to verify that mounting and

197 handling were satisfactory as well as to obtain some initial selectivity data from a limited

198 number of hauls. (Further data was obtained in the LANGRID 1 and 2 campaigns in 2003,

199 before trials on commercial vessels began). The details of the grid mounting are given in

200 Figure 9. The grid is inclined at $45^{\circ}$ to the horizontal. In all cases the twin trawl technique was

201 employed to allow a direct comparison between hauls with two nets of $70 \mathrm{~mm}$ as-gauged (40

202 mm edge) polyethylene braid mesh, Figure 10. Apart from their codends the two trawls were

203 identical. The grid was placed in one net, as shown in Figure 11. In the other (the reference

204 net) a fine $20 \mathrm{~mm}$ as-gauged mesh polyamide inner bag was placed in the codend to retain all

205 the species entering. The grid test trawl codend was in standard $70 \mathrm{~mm}$ as-gauged breizline.

206 The difference between the catch in the two nets thus indicates the influence of the grid 207 together with the standard codend on selectivity.

208

209 The nets were used in the same position throughout, they were not inverted to eliminate bias

210 as these were preliminary tests and only a short testing period was available. For each haul

211 and both nets the nephrops catch was weighed and measured and certain other individual 212 species were also weighed. A total of 6 hauls were performed, in the CIEM VIIIa Sud 213 Bretagne sector in 90 to 120 meters water depth, each lasting on average 2.5 hours. Average 214 vessel speed during fishing was 3.5 knots. Table 1 shows the weights caught for each haul. 215 The rejects included large quantities of horse mackerel plus various debris. Table 2 shows the 216 numbers of nephrops by length category. Figure 12 is a plot of these results for all the 217 nephrops individuals versus length. 
219 These data indicate that the grid with the $70 \mathrm{~mm}$ mesh codend reduces the number of 220 juveniles caught by $88 \%$ and their weight by $87 \%$ However, it also shows that with this grid 221 spacing the commercial catch was reduced by $61 \%$ by number and $53 \%$ by weight.

223 The length data for all hauls were analysed using the SELECPARA software. This is a 224 programme using the method developed by Millar and Walsh (1990), often referred to as the 225 SELECT (Share Each Length Catch Total) method, to fit a logistic selectivity curve to trouser 226 trawl data. Individual hauls were not analysed due to the small quantities of catch.

228 Figure 13 shows the results from the statistical analysis From these data it is possible to 229 determine the values of L50 and the selection range, Table 3 . There is some scatter, 230 particularly for the larger nephrops, which is not unexpected given the small number of hauls. 231 Variance values for each parameter are also given, an approximate 95\% confidence is given 232 by an interval of plus or minus two standard deviations around the estimate (Wileman et al. 233 1996).

\section{Discussion and Conclusions}

The results from these first trials were very promising. The crew found the light weight of the grid $(10 \mathrm{~kg})$ made handling very easy. There were no concerns with damage during hauling and the grid was easily stored on the drum without requiring any particular precautions. It

240 should be noted that drum diameters do vary between vessels, and the influence of very tight 241 bending radii on small drums may need to be addressed. During hauling the grid does not 
242 necessarily arrive perpendicular to the drum, as shown in Figure 14, and a combination of

243 flexure (in both width and height directions) and torsion may be imposed. However, as shown

244 in Figure 2, there is considerable scope for improving damage resistance by reducing the

245 Shore hardness if necessary. Subsequent experience with both this grid and alternative designs

246 for selectivity of other species suggested that a further increase in flexibility might be

247 advantageous for long term durability (repeated bending). This is being investigated in a 248 current study.

250 The preliminary selectivity data, albeit from a small catch sample, suggest that flexible grids 251 can provide interesting selection characteristics. The lower stiffness of the bars compared to 252 metal can be compensated by design. Further sea trial data are clearly necessary to confirm 253 this and quantify the selectivity characteristics. Nevertheless there appears to be a significant 254 reduction in juvenile catch, which justifies pursuing the evaluation of flexible grids, but also 255 an unacceptably high loss of commercial catch. These trials used a $20 \mathrm{~mm}$ bar spacing. A 256 reduction would certainly be beneficial and in subsequent tests and commercial trials 18 and $25715 \mathrm{~mm}$ spacings were employed.

259 Polyurethane polymers offer a wide range of possibilities for fishing grids. Their light weight 260 and ease of handling are beneficial for safety and their flexibility allows them to pass over 261 drum rollers repeatedly without damage. Simple fabrication results in low cost and complex 262 cross-sections (circular for example, or with improved hydrodynamic profiles) can be 263 produced industrially. 
265 Other studies of flexible selectivity grids being performed in parallel have indicated 266 promising performance for other species and this work is continuing to optimise the concept. 


\section{References}

Briggs RP, Armstrong MJ, Rihan D, (1999), The consequences of an increase in mesh size in the Irish Sea Nephrops fishery: an experimental approach, Fish. Res., 40, 45-53.

Eigaard OR, Holst R, The effective selectivity of a composite gear for industrial fishing : a sorting grid in combination with a square mesh window, Fish. Res., 68, 99-112.

Fonseca P, Campos A, Larsen RB, Borges TC, Erzini K, Using a modified Nordmore grid for by-catch reduction in the Portuguese crustacean-trawl fishery, Fish. Res., 71, 223-239.

Frid CLJ, (2001), NETRASEL (Nephrops trawl discard reduction using activating selection grids), European project FAIR984164, Executive summary, March.

Graham N, (2003), By-catch reduction in the brown shrimp (Crangon crangon) fisheries using a rigid sorting Nordmore grid (grate), Fish. Res., 59, 393-407.

Graham N, O’Neill FG, Fryer RJ, Galbraith RD, Myklebust A, Selectivity of a $120 \mathrm{~mm}$ diamond cod-end and the effect of inserting a rigid grid or a square mesh panel, Fish Res., 67, 151-161.

Isaksen B, Valdermersen JW, Larsen RB, Karlsen L, (1992), Reduction of fish by-catch in shrimp trawl using a rigid sorting grid in the aft belly, Fish. Res., 13, 335-352. 
Kvamme C, Isaksen B, (2004), Total selectivity of commercial cod trawl with and without a grid mounted,: grid and codend selectivity of north-east Artic cod, Fish. Res., 68, 305-318.

Larsen RB, Isaksen B (1993) Size selectivity of rigid sorting grids in bottom trawls for Atlantic cod and haddock, ICES Mar Sci Symp, 196, 178-182.

Madsen N, Moth-Poulsen T, Holst R, Wileman D, (1999), Selectivity experiments with escape windows in the North Sea Nephrops (Nephrops norvegicus) trawl fishery, Fish. Res., $42,167-181$

Meillat, M., Dupouy, H., et al. (1994), Preliminary results of a trawl fitted with a selective grid for the fishery of benthic species from Celtic sea and Bay of Biscay. International Council for Exploitation of the sea. Fish capture committee CM1994 B:23 Ref.G. (Available from M. Meillat, IFREMER Centre de Lorient, 56100 Lorient, France).

Millar RB, Walsh (1990) Analysis of trawl selectivity studies with an application to trouser trawls, ICES CM 1990, B14, 1-14.

Polet H, (2002) Selectivity experiments with sorting grids in the North Sea brown shrimp (Crangon crangon) fishery, Fish Res., 54, 217-233.

Polet H, Coenjaerts J, Verschoore R, (2004) Evaluation of the sieve net as a selectivity improving device in the Belgian brown shrimp (Crangon crangon) fishery, Fish. Res. 69, 3548. 
Wileman DA, Ferro RST, Fonteyne R, Millar RB (eds), (1996), Manual of methods of measuring the sensitivity of towed fishing gears, ICES cooperative research report no. 215. 


\begin{tabular}{|c|c|c|c|c|c|c|c|c|c|c|c|}
\hline $\begin{array}{l}\text { Haul } \\
\text { no. }\end{array}$ & & nephrops & hake & monkfish & megrim & dogfish & cephalopod & mullet & sole & diverse & reject \\
\hline 1 & $\begin{array}{l}\text { Ref. } \\
\text { Grid }\end{array}$ & $\begin{array}{l}1.5 \\
1\end{array}$ & $\begin{array}{l}3.6 \\
4.2\end{array}$ & 0.85 & & & $\begin{array}{l}1.2 \\
0.4\end{array}$ & $\begin{array}{l}0.4 \\
0.9\end{array}$ & $\begin{array}{l}0.1 \\
0.4\end{array}$ & 2.9 & $\begin{array}{l}14.2 \\
11.8\end{array}$ \\
\hline 2 & $\begin{array}{l}\text { Ref. } \\
\text { Grid }\end{array}$ & $\begin{array}{l}5.7 \\
4.3\end{array}$ & $\begin{array}{l}2.3 \\
5.9\end{array}$ & $\begin{array}{l}2.5 \\
0.7\end{array}$ & & & $\begin{array}{l}0.8 \\
0.8\end{array}$ & $\begin{array}{l}0.8 \\
1.3\end{array}$ & $\begin{array}{l}0.9 \\
0.4\end{array}$ & $\begin{array}{l}3.4 \\
0.2\end{array}$ & $\begin{array}{l}27.9 \\
31.6\end{array}$ \\
\hline 3 & $\begin{array}{l}\text { Ref. } \\
\text { Grid }\end{array}$ & $\begin{array}{l}18 \\
5.8\end{array}$ & $\begin{array}{l}4 \\
3.9\end{array}$ & $\begin{array}{l}7.6 \\
5.6\end{array}$ & $\begin{array}{l}1.0 \\
0.6\end{array}$ & & $\begin{array}{l}2.1 \\
2.8\end{array}$ & 1.72 & $\begin{array}{l}1.2 \\
0.6\end{array}$ & 0.2 & $\begin{array}{l}38 \\
16\end{array}$ \\
\hline 4 & $\begin{array}{l}\text { Ref. } \\
\text { Grid }\end{array}$ & $\begin{array}{l}19.4 \\
4.5\end{array}$ & $\begin{array}{l}12.4 \\
8.5\end{array}$ & $\begin{array}{l}6.9 \\
0.5\end{array}$ & $\begin{array}{l}2.7 \\
1.8\end{array}$ & 1.6 & $\begin{array}{l}7.6 \\
3.6\end{array}$ & $\begin{array}{l}1.1 \\
0.6\end{array}$ & 1.3 & $\begin{array}{l}2 \\
6.8\end{array}$ & $\begin{array}{l}51 \\
26.2\end{array}$ \\
\hline 5 & $\begin{array}{l}\text { Ref. } \\
\text { Grid }\end{array}$ & $\begin{array}{l}7.9 \\
3.1\end{array}$ & $\begin{array}{l}6 \\
4.5\end{array}$ & 1.4 & $\begin{array}{l}2 \\
0.7\end{array}$ & & $\begin{array}{l}5.3 \\
2.9\end{array}$ & $\begin{array}{l}0.6 \\
1.2\end{array}$ & $\begin{array}{l}1.2 \\
0.6\end{array}$ & $\begin{array}{l}1.1 \\
4.8\end{array}$ & $\begin{array}{l}21 \\
16.7\end{array}$ \\
\hline 6 & $\begin{array}{l}\text { Ref. } \\
\text { Grid }\end{array}$ & $\begin{array}{l}6.7 \\
4.6\end{array}$ & $\begin{array}{l}4.5 \\
8.6\end{array}$ & 2.9 & & $\begin{array}{l}3.3 \\
2.2\end{array}$ & $\begin{array}{l}3.7 \\
4.1\end{array}$ & 1.5 & $\begin{array}{l}0.2 \\
1.5\end{array}$ & $\begin{array}{l}1 \\
0.6\end{array}$ & $\begin{array}{l}32 \\
59\end{array}$ \\
\hline Total & Ref. & 59.2 & 32.8 & 18.4 & 5.7 & 3.3 & 20.8 & 3 & 3.6 & 7.5 & 183.8 \\
\hline Total & Grid & 23.2 & 35.5 & 10.5 & 3.1 & 3.8 & 14.6 & 7.2 & 4.8 & 15.4 & 161.1 \\
\hline
\end{tabular}

Table 1. Campaign SELMERL1, 20mm grid spacing, all species by weight (kg). 


\begin{tabular}{|c|c|c|}
\hline length & Number & Number \\
\hline carapace, $\mathrm{mm}$ & TOTAL REF. & TOTAL GRID \\
\hline 10 & 0 & 0 \\
\hline 11 & 0 & 0 \\
\hline 12 & 12 & 0 \\
\hline 13 & 0 & 0 \\
\hline 14 & 0 & 0 \\
\hline 15 & 12 & 2 \\
\hline 16 & 14 & 0 \\
\hline 17 & 48 & 0 \\
\hline 18 & 45 & 3 \\
\hline 19 & 44 & 6 \\
\hline 20 & 106 & 7 \\
\hline 21 & 74 & 11 \\
\hline 22 & 146 & 22 \\
\hline 23 & 224 & 21 \\
\hline 24 & 226 & 43 \\
\hline total undersize & 950 & 114 \\
\hline 25 & 418 & 68 \\
\hline 26 & 375 & 84 \\
\hline 27 & 359 & 103 \\
\hline 28 & 278 & 77 \\
\hline 29 & 188 & 86 \\
\hline 30 & 297 & 117 \\
\hline 31 & 130 & 77 \\
\hline 32 & 143 & 105 \\
\hline 33 & 71 & 51 \\
\hline 34 & 76 & 65 \\
\hline 35 & 72 & 48 \\
\hline 36 & 46 & 28 \\
\hline 37 & 41 & 39 \\
\hline 38 & 44 & 24 \\
\hline 39 & 17 & 17 \\
\hline 40 & 24 & 18 \\
\hline 41 & 3 & 7 \\
\hline 42 & 10 & 6 \\
\hline 43 & 0 & 3 \\
\hline 44 & 19 & 3 \\
\hline 45 & 10 & 3 \\
\hline 46 & 6 & 0 \\
\hline 47 & 2 & 1 \\
\hline 48 & 0 & 3 \\
\hline 49 & 2 & 0 \\
\hline 50 & 2 & 0 \\
\hline 51 & 0 & 1 \\
\hline 52 & 0 & 0 \\
\hline 53 & 0 & 1 \\
\hline 54 & 0 & 0 \\
\hline 55 & 0 & 0 \\
\hline total commercial & 2632 & 1033 \\
\hline
\end{tabular}

Table 2. Numbers of nephrops versus length category, all hauls. 


\begin{tabular}{|c|c|c|c|}
\hline Parameter & Value, $\mathrm{mm}$ & Variance & Standard deviation \\
\hline L1\% & 14.3 & 0.25 & 0.50 \\
L5\% & 19.1 & 0.12 & 0.34 \\
L25\% & 26.0 & 0.03 & 0.16 \\
L50\% & $\mathbf{3 0 . 8}$ & $\mathbf{0 . 0 3}$ & $\mathbf{0 . 1 7}$ \\
L75\% & 35.5 & 0.08 & 0.29 \\
L95\% & 42.4 & 0.26 & 0.51 \\
L99\% & 47.2 & 0.45 & 0.67 \\
\hline
\end{tabular}

Table 3. Selectivity statistics, $20 \mathrm{~mm}$ spacing grid with $70 \mathrm{~mm}$ codend. 


\section{Figure headings}

Figure 1. Position of grid in trawl net

Figure 2. Stress-strain behaviour of different PU formulations measured on cast $\mathrm{H}-2$ dogbone specimens (insert photo).

Figure 3. Residual tensile strength of PU Shore $90 \mathrm{~A}$ after aging in artificial sea water at $50^{\circ} \mathrm{C}$ for periods up to 2 years. 5 specimens tested wet, 5 tested after drying to constant weight. Error bars show standard deviations.

Figure 4. Casting into a wooden mould.

Figure 5. Flexural response of Shore 50D hardness bar element.

Figure 6. Connecting elements. a) geometry, b) FE simulation showing initial and deformed shape for load of $100 \mathrm{~N}$.

Figure 7. Grid on test frame during folding tests.

Figure 8. Description of grid used for sea trials.

Figure 9. Grid equipment for sea trials.

Figure 10. Details of net configuration, top and bottom dimensions.

Figure 11. View inside net showing grid mounting.

Figure 12 Total nephrops catch, all hauls by carapace length compared to mls (minimum landing size of $25 \mathrm{~mm})$.

Figure 13. Selectivity distribution, $20 \mathrm{~mm}$ spacing grid with $70 \mathrm{~mm}$ as gauged codend, versus carapace length.

Figure 14. Grid in net just before passing onto drum roller. 


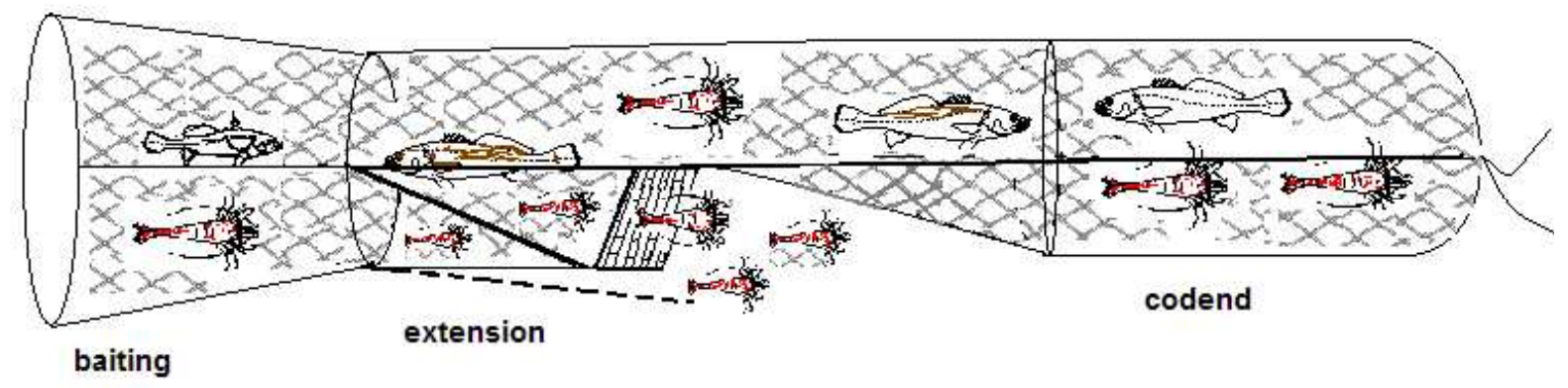

Figure 1. Schematic diagram showing the position of the grid in trawl net. 


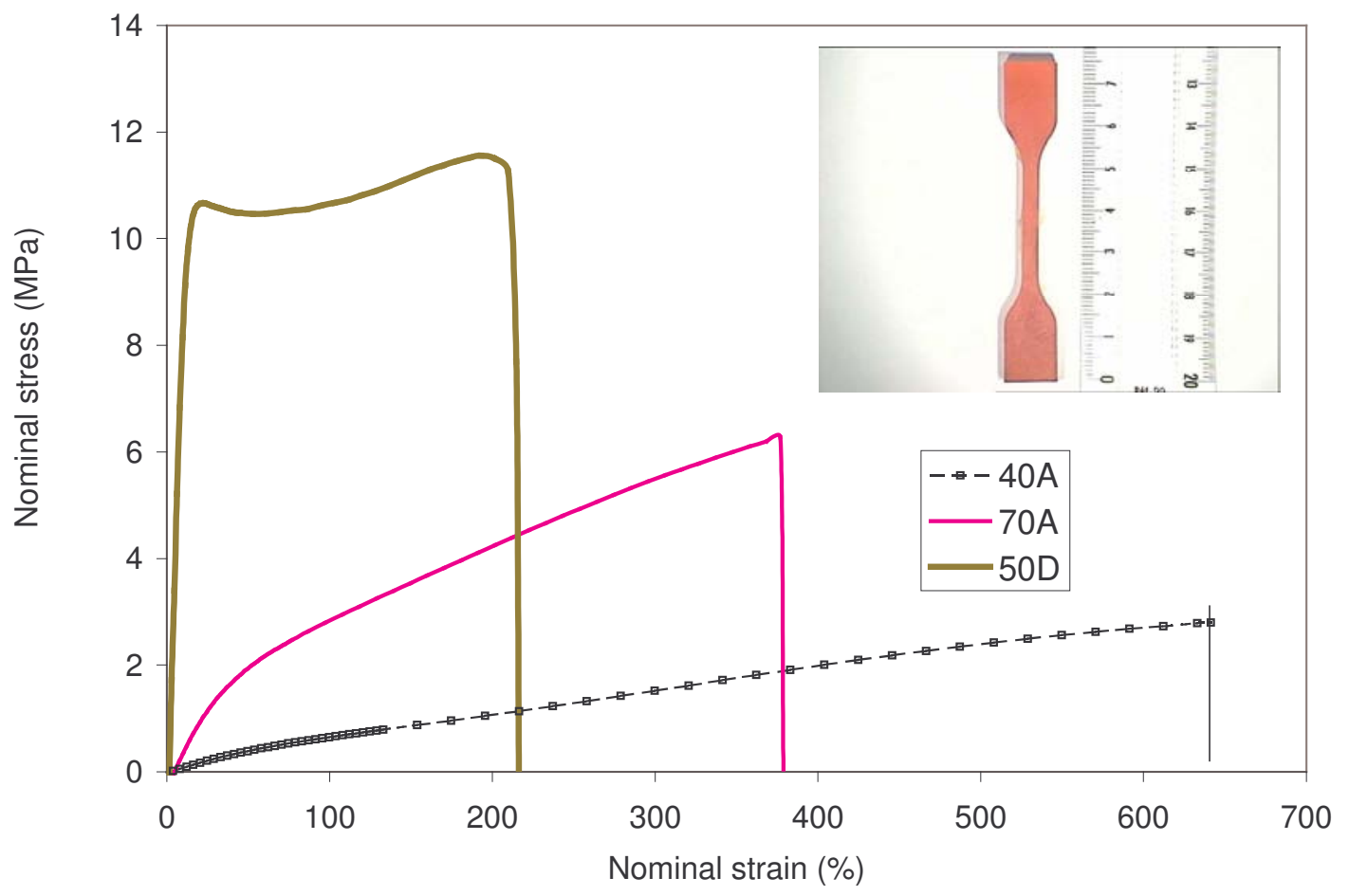

Figure 2. Stress-strain behaviour of different PU formulations measured on cast $\mathrm{H}-2$ dog-bone specimens (insert photo). 


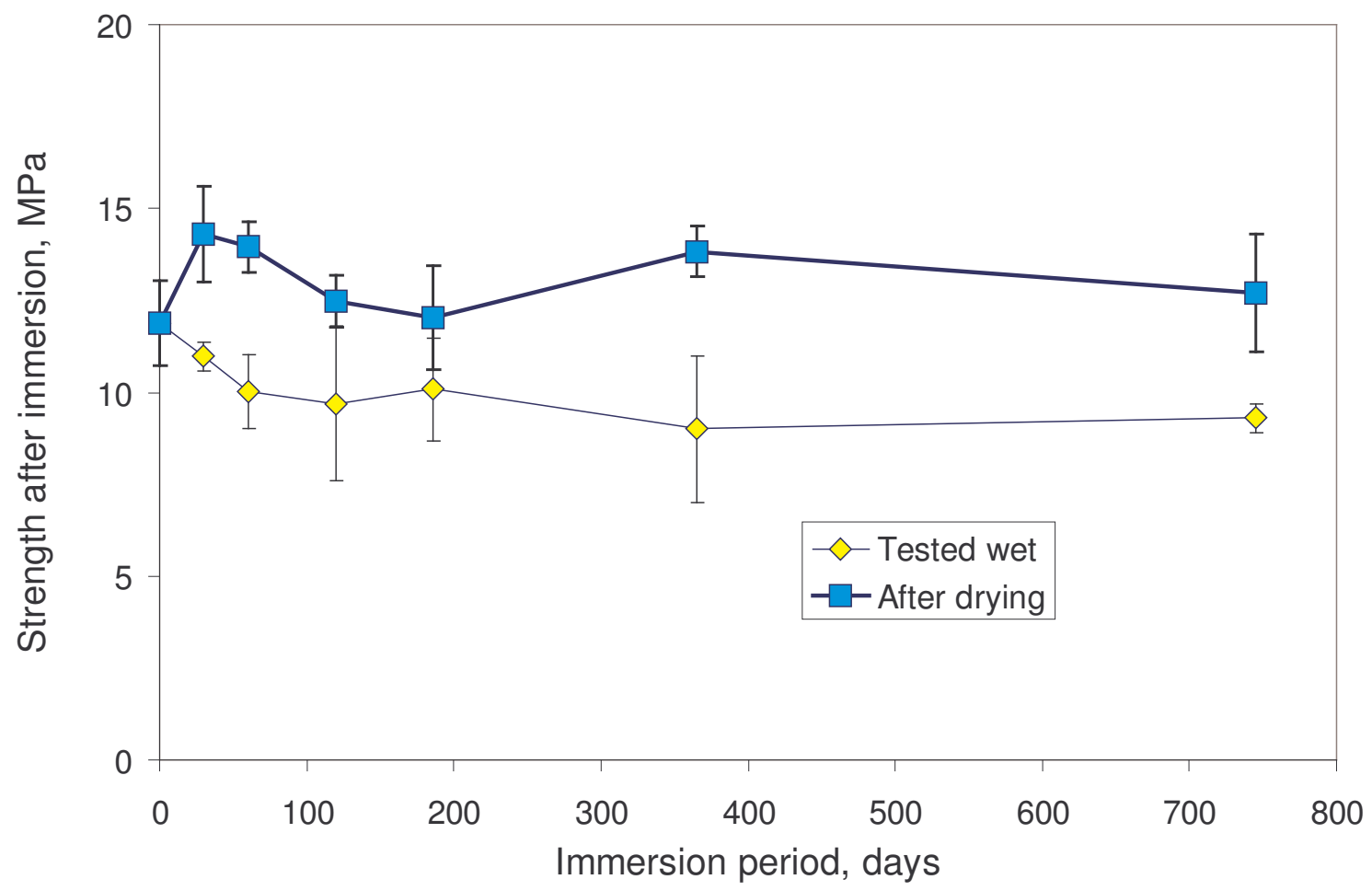

Figure 3. Residual tensile strength of PU Shore $90 \mathrm{~A}$ after aging in artificial sea water at $50^{\circ} \mathrm{C}$ for periods up to 2 years. 5 specimens tested wet, 5 tested after drying to constant weight. Error bars show standard deviations. 


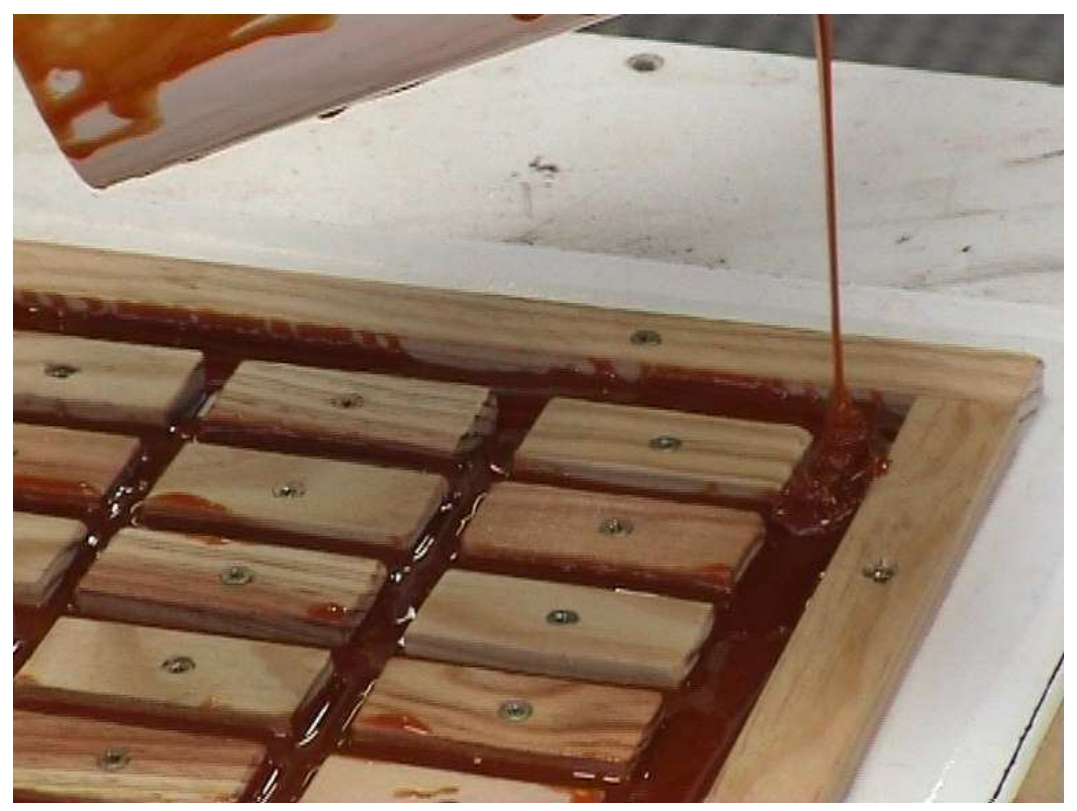

Figure 4. Casting into a wooden mould. 


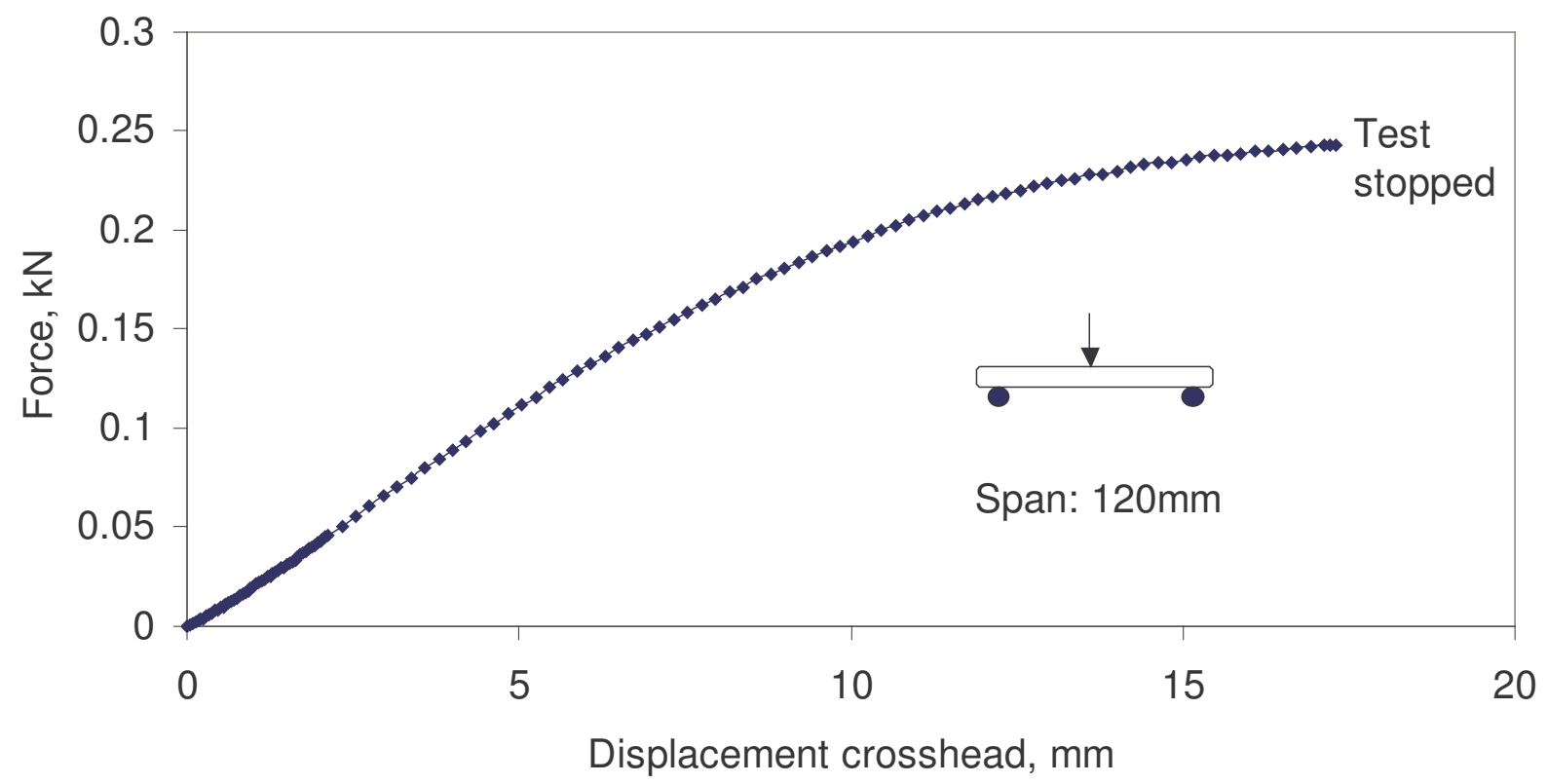

Figure 5. Flexural response of Shore 50D hardness bar element (13 mm thick). 

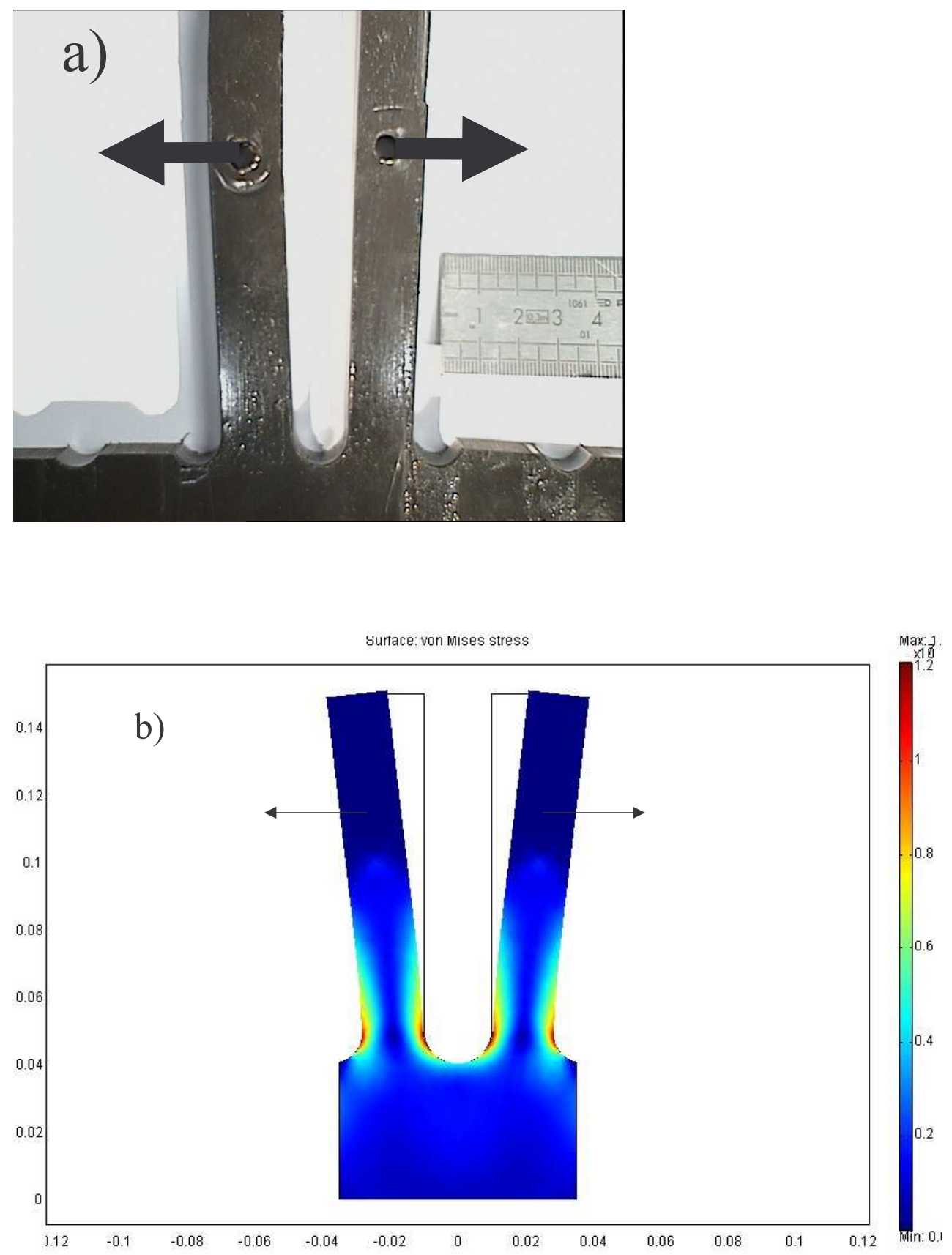

Figure 6. Connecting elements. a) geometry, b) FE simulation showing initial and deformed shape for load of $100 \mathrm{~N}$. 


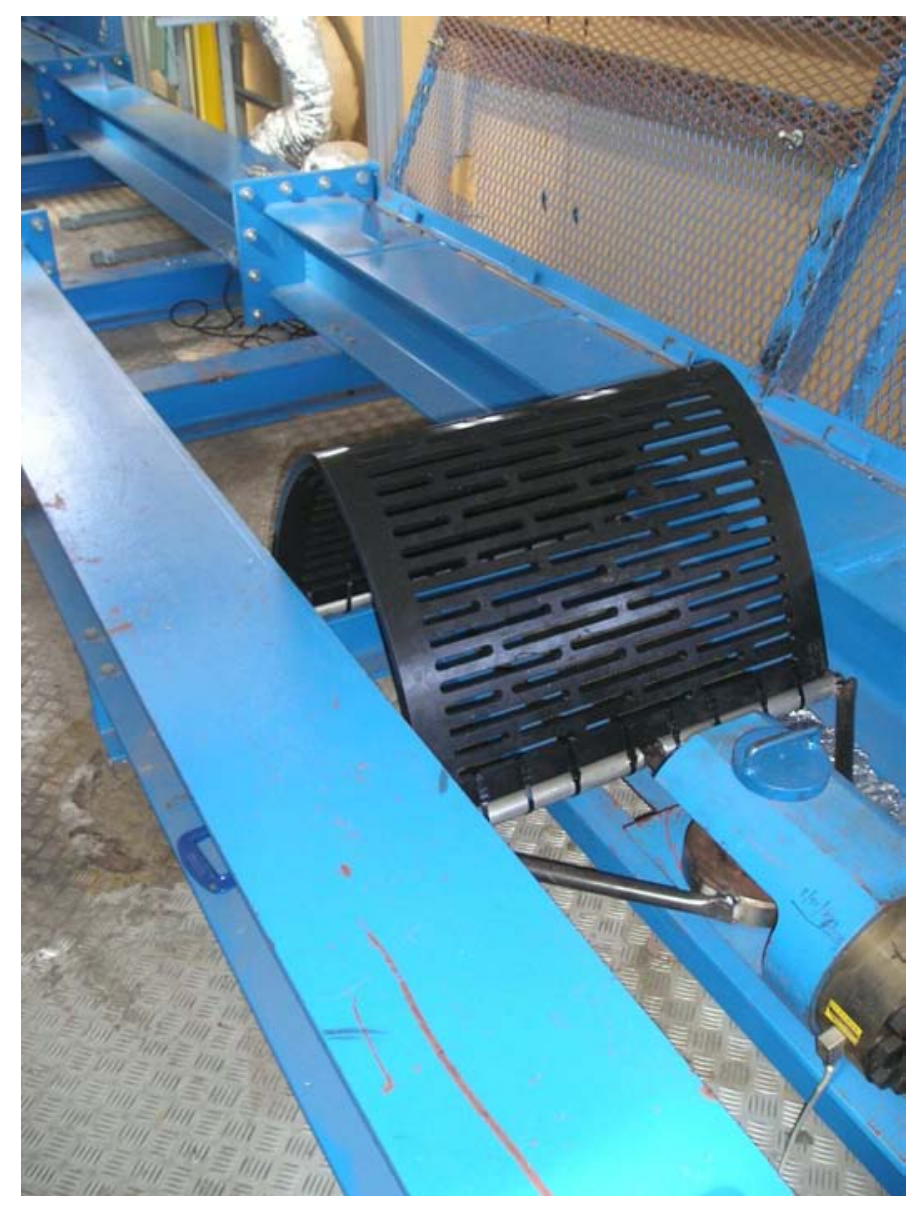

Figure 7. Grid on test frame during folding tests 
Grid shape : Square

Dimensions : Width $1 \mathrm{~m}$, Height $1 \mathrm{~m}$

Bar spacing : $20 \mathrm{~mm}$

Material : Polyurethane Shore 50D

Registered reference name: Evaflex

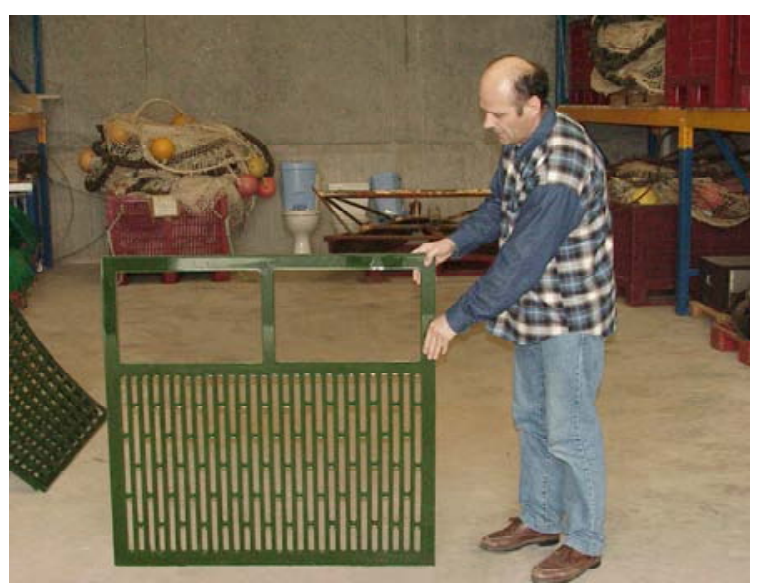

Figure 8. Description of grid used for preliminary sea trials 


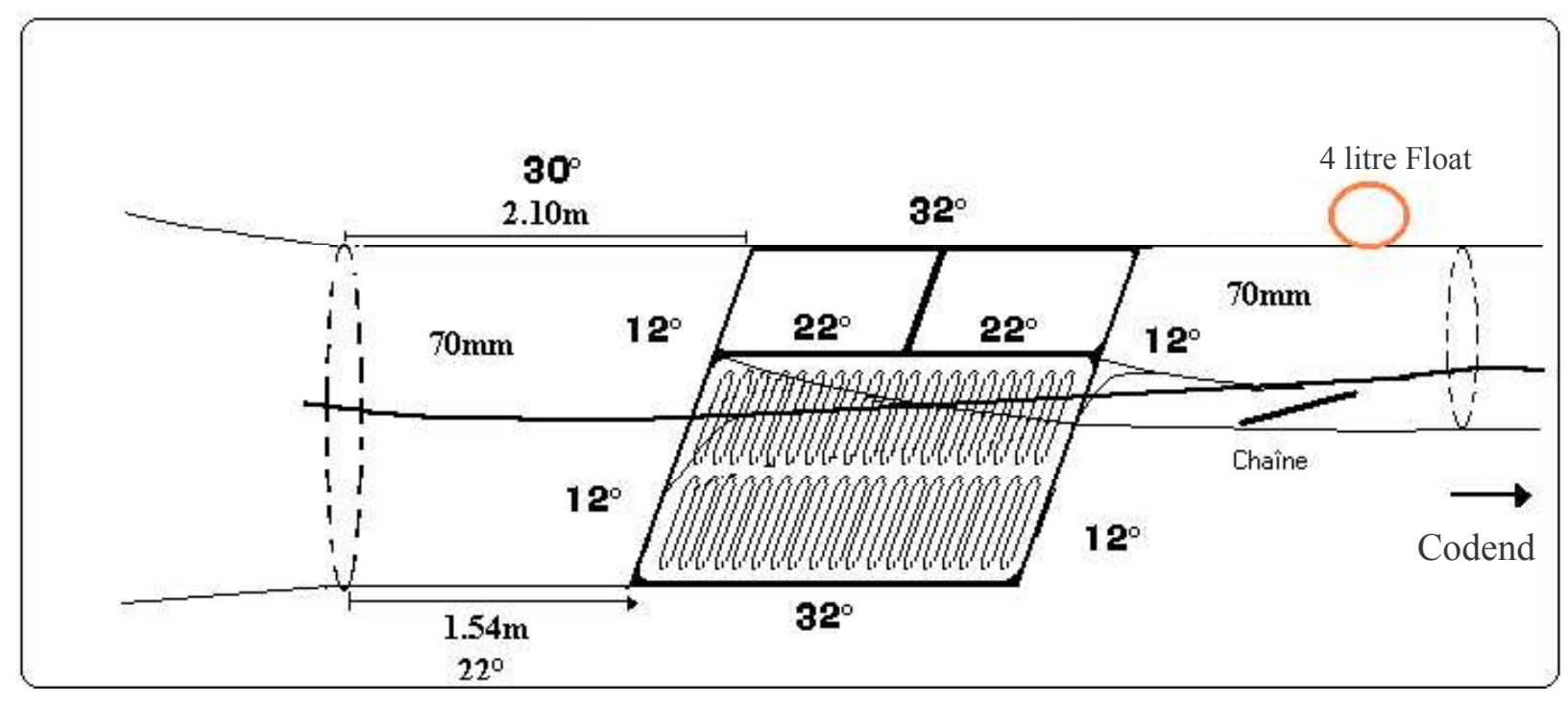

Figure 9. Grid mounting details $\left(30^{\circ}=30\right.$ mesh units $)$. 


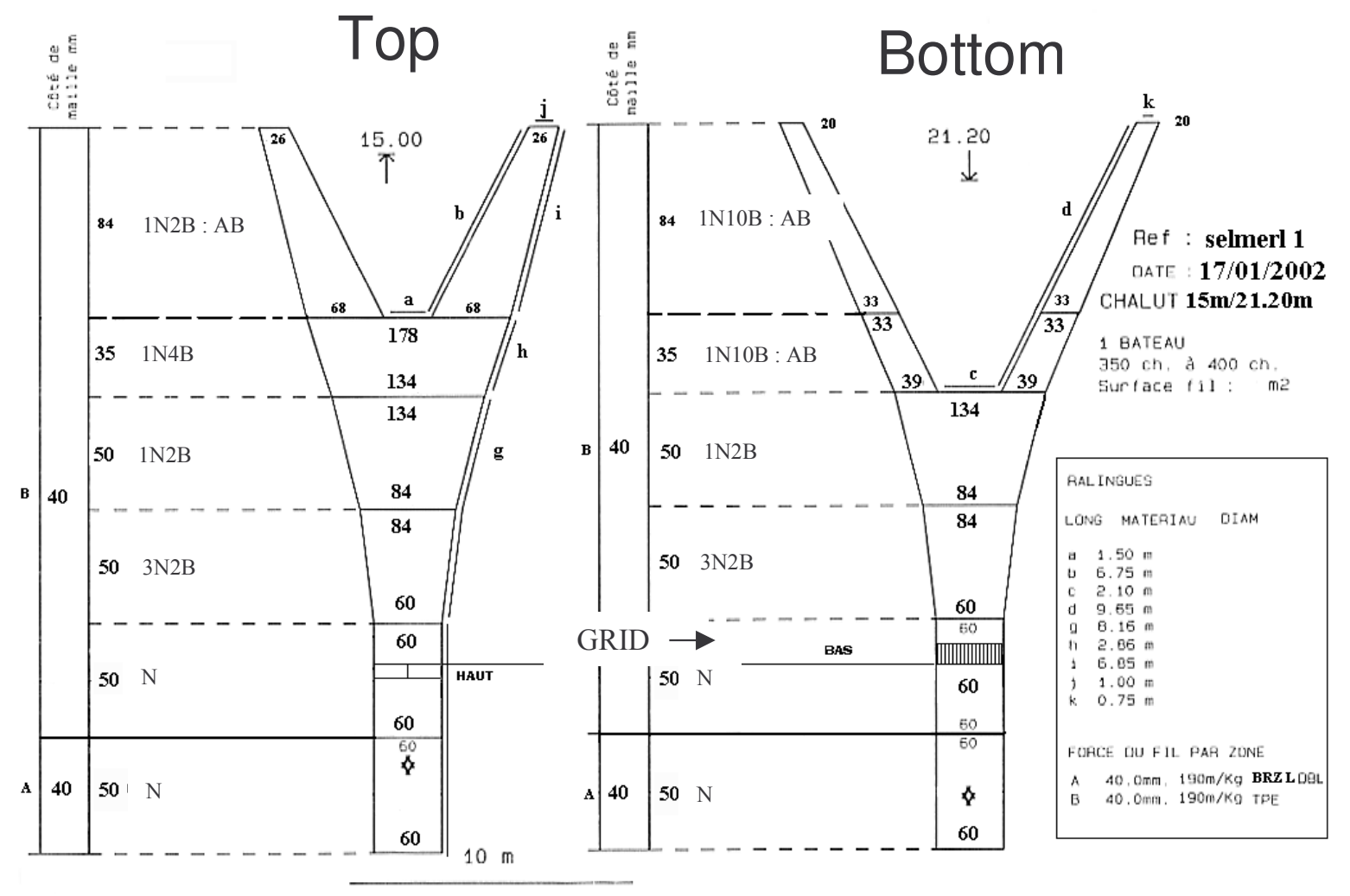

Figure 10. Details of net configuration, top and bottom dimensions. 


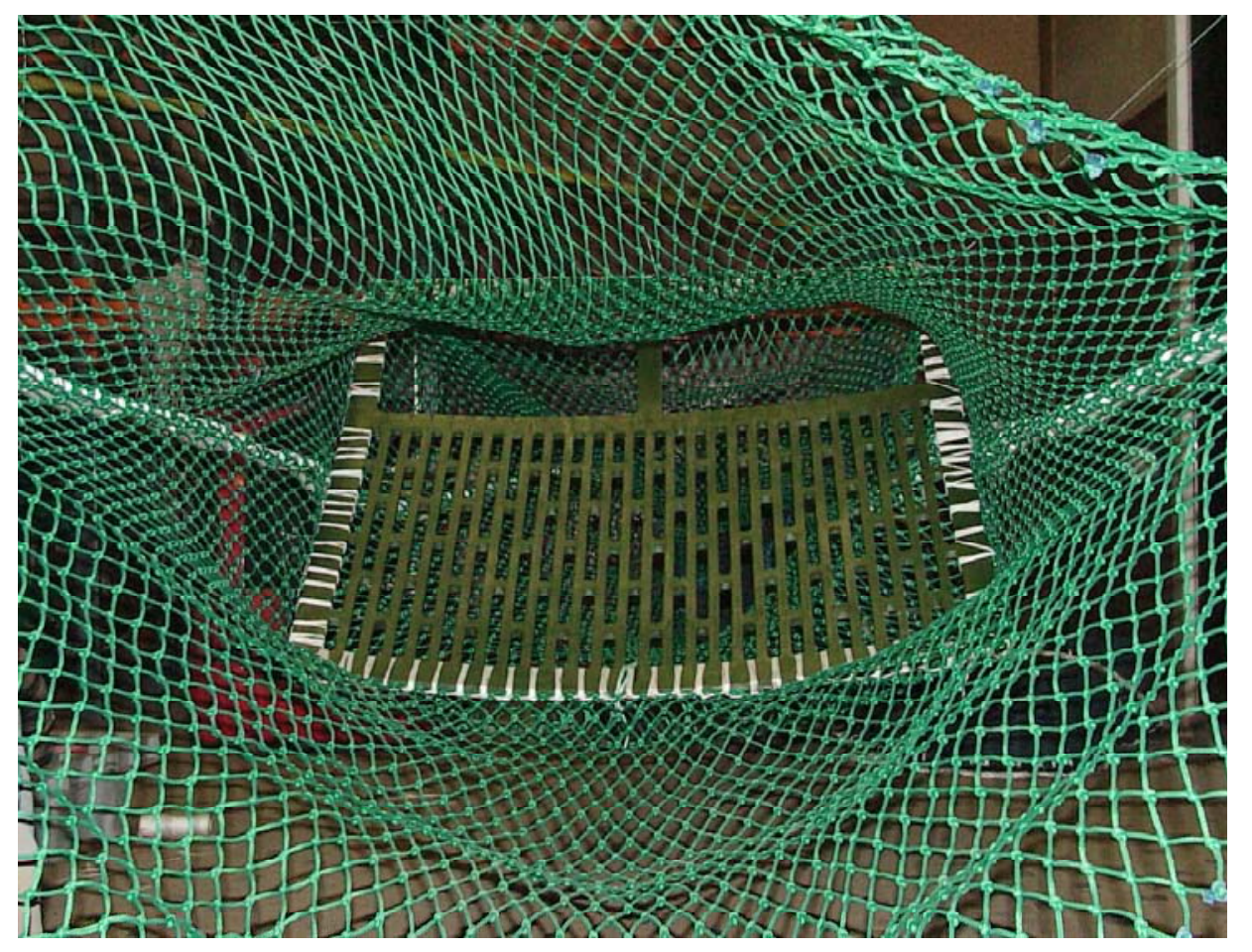

Figure 11. View inside net showing grid mounting. 


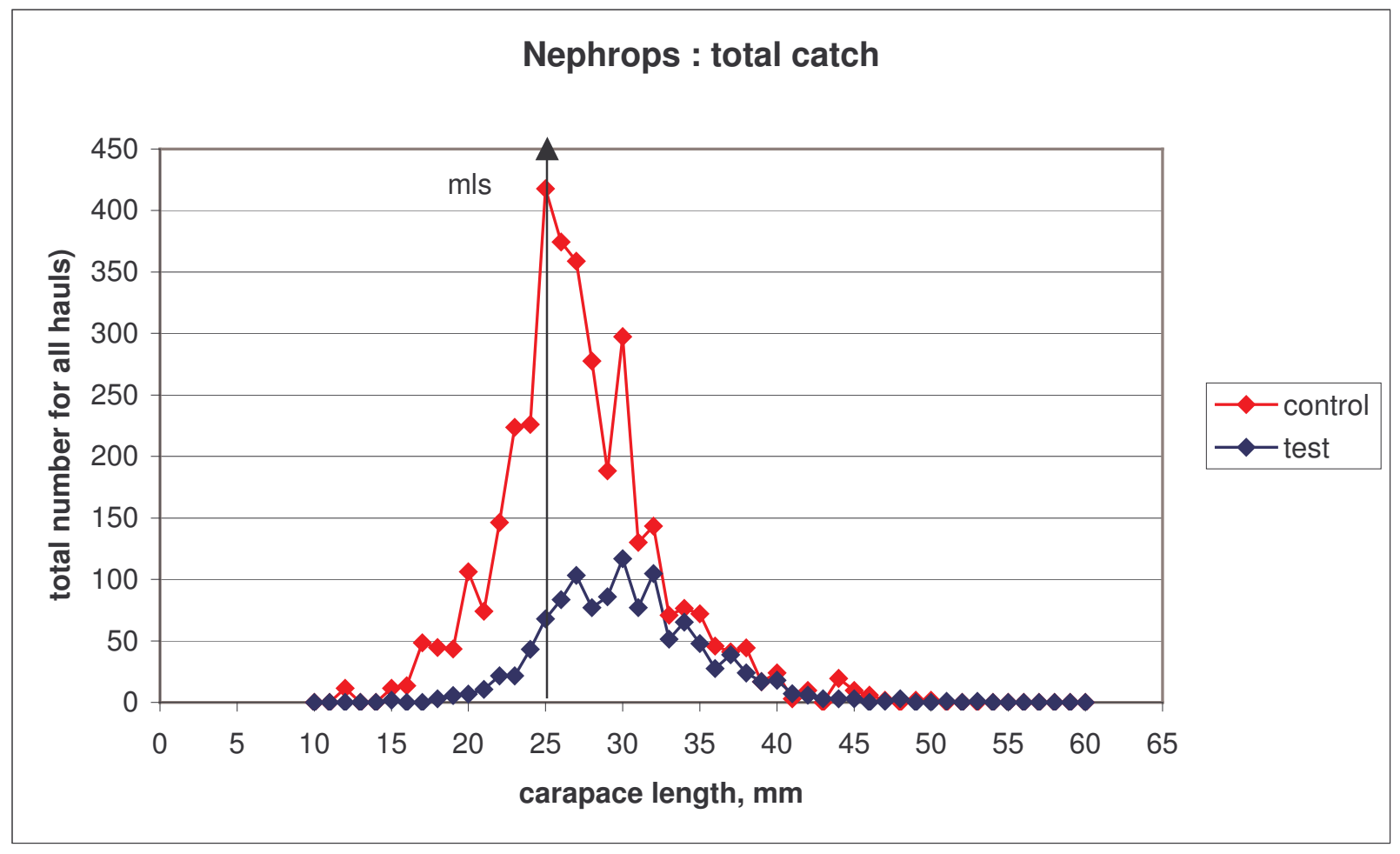

Figure 12. Total nephrops catch, all hauls by carapace length compared to mls (minimum landing size of $25 \mathrm{~mm}$ ). 


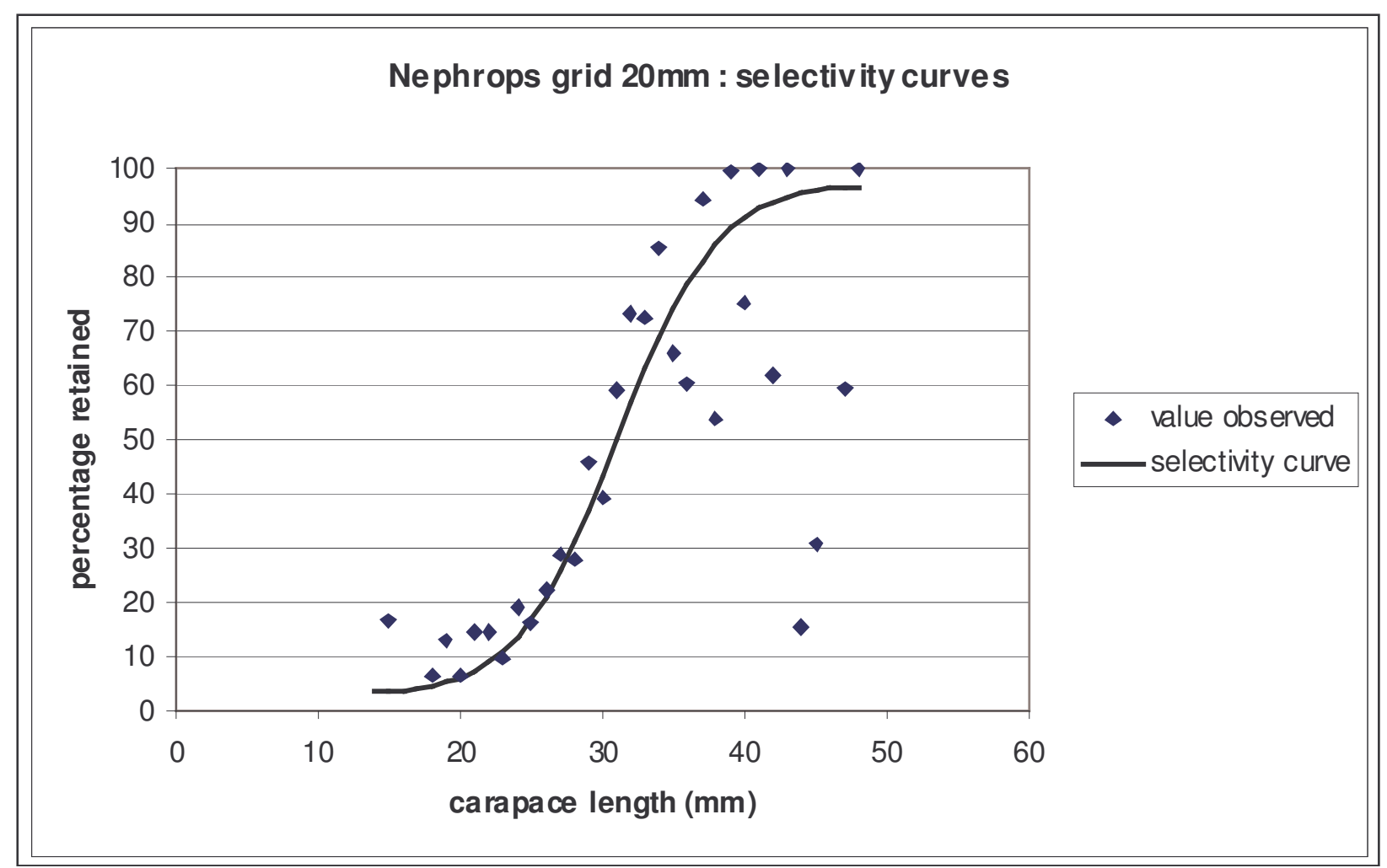

Figure 13. Selectivity distribution, $20 \mathrm{~mm}$ spacing grid with $70 \mathrm{~mm}$ as gauged codend, versus carapace length. 


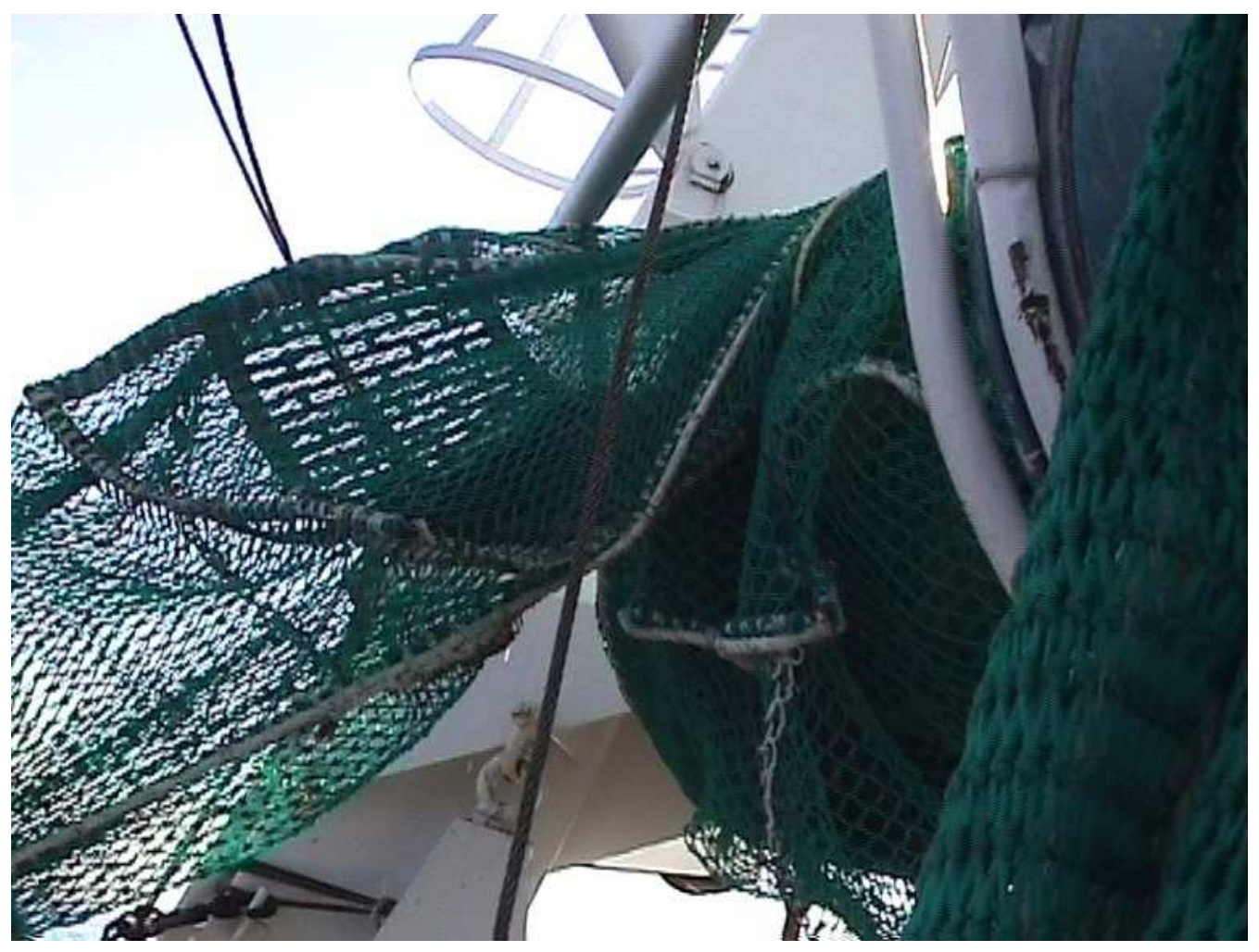

Figure 14. Grid in net just before passing onto drum roller. 